\title{
Auditory P300 and N100 components as intermediate phenotypes for psychotic disorder: Familial liability and reliability
}

Citation for published version (APA):

Simons, C. J. P., Sambeth, A., Krabbendam, A. C., Pfeifer, S., van Os, J. J., \& Riedel, W. J. (2011). Auditory P300 and N100 components as intermediate phenotypes for psychotic disorder: Familial liability and reliability. Clinical Neurophysiology, 122(10), 1984-1990. https://doi.org/10.1016/j.clinph.2011.02.033

Document status and date:

Published: 01/01/2011

DOI:

10.1016/j.clinph.2011.02.033

Document Version:

Publisher's PDF, also known as Version of record

\section{Document license:}

Taverne

Please check the document version of this publication:

- A submitted manuscript is the version of the article upon submission and before peer-review. There can be important differences between the submitted version and the official published version of record.

People interested in the research are advised to contact the author for the final version of the publication, or visit the DOI to the publisher's website.

- The final author version and the galley proof are versions of the publication after peer review.

- The final published version features the final layout of the paper including the volume, issue and page numbers.

Link to publication

\footnotetext{
General rights rights.

- You may freely distribute the URL identifying the publication in the public portal. please follow below link for the End User Agreement:

www.umlib.nl/taverne-license

Take down policy

If you believe that this document breaches copyright please contact us at:

repository@maastrichtuniversity.nl

providing details and we will investigate your claim.
}

Copyright and moral rights for the publications made accessible in the public portal are retained by the authors and/or other copyright owners and it is a condition of accessing publications that users recognise and abide by the legal requirements associated with these

- Users may download and print one copy of any publication from the public portal for the purpose of private study or research.

- You may not further distribute the material or use it for any profit-making activity or commercial gain

If the publication is distributed under the terms of Article $25 \mathrm{fa}$ of the Dutch Copyright Act, indicated by the "Taverne" license above, 


\title{
Auditory P300 and N100 components as intermediate phenotypes for psychotic disorder: Familial liability and reliability
}

\author{
Claudia J.P. Simons ${ }^{\mathrm{a}, \mathrm{b}, *}$, Anke Sambeth ${ }^{\mathrm{c}}$, Lydia Krabbendam ${ }^{\mathrm{a}, \mathrm{e}}$, Stefanie Pfeifer ${ }^{\mathrm{a}}$, Jim van Os ${ }^{\mathrm{a}, \mathrm{d}}$, \\ Wim J. Riedel ${ }^{\mathrm{c}}$

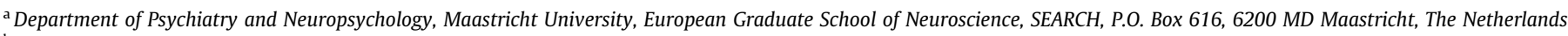 \\ ${ }^{\mathrm{b}}$ GGzE, Institute of Mental Health Care Eindhoven en de Kempen, P.O. Box 909, 5600 AX Eindhoven, The Netherlands \\ ${ }^{\mathrm{c}}$ Department of Neuropsychology and Psychopharmacology, Faculty of Psychology and Neuroscience, Maastricht University, P.O. Box 616, 6200 MD Maastricht, The Netherlands \\ ${ }^{\mathrm{d}}$ Visiting Professor of Psychiatric Epidemiology, King's College London, King's Health Partners, Department of Psychosis Studies, Institute of Psychiatry, UK \\ ${ }^{\mathrm{e}}$ Centre Brain and Learning, Department of Psychology and Education, VU University Amsterdam, van der Boechorststraat 1, 1081 BT Amsterdam, The Netherlands
}

\section{A R T I C L E I N F O}

Article history:

Accepted 28 February 2011

Available online 1 April 2011

\section{Keywords:}

Electroencephalography

Event-related potentials

Psychoses

Schizophrenia

Test-retest

Relatives

\section{H I G H L I G H T S}

- A reliable N100 latency delay was found in unaffected siblings of patients with a psychotic disorder. - P300 amplitude and latency were not found to be affected in siblings.

- Short-term test-retest reliability of N100 and P300 components were sound across patients, siblings and controls, with the main exception of N100 latency in patients.

\begin{abstract}
A B S T R A C T
Objective: Abnormalities of the auditory P300 are a robust finding in patients with psychosis. The purposes of this study were to determine whether patients with a psychotic disorder and their unaffected siblings show abnormalities in P300 and N100 and to establish test-retest reliabilities for these ERP components.

Methods: Using an auditory oddball paradigm, P300 and N100 latency and amplitude were acquired from 19 patients with a psychotic disorder, 28 unaffected siblings, and 37 healthy controls, on two separate occasions. ERP components were compared between groups, using multilevel random regression analyses. Intraclass correlations were used to determine consistency of ERP components between the sessions. Results: A delayed target N100 latency was found in unaffected siblings. Patients showed significantly delayed P300 latency and diminished P300 amplitude compared to controls. Most ERP parameters showed good test-retest reliability. However, patients did not show sufficient reliability for N100 latency for standard stimuli.

Conclusions: The present study failed to find significant P300 abnormalities in unaffected siblings. However, N100 latency is delayed in siblings and can be reliably measured in all groups for target stimuli, suggesting that this component, rather than P300, may serve as liability marker.

Significance: N100 latency is a promising biomarker for psychosis liability.
\end{abstract}

(c) 2011 International Federation of Clinical Neurophysiology. Published by Elsevier Ireland Ltd. All rights

reserved.

\section{Introduction}

Schizophrenia is a highly heritable disorder (Gottesman, 1991; Cardno and Gottesman, 2000). However, genetic association studies have, as yet, failed to provide consistent results regarding the precise mode of transmission of the genetic vulnerability. The genetic

\footnotetext{
* Corresponding author at: Department of Psychiatry and Neuropsychology, Maastricht University, European Graduate School of Neuroscience, SEARCH, P.O. Box 616 (Vijv1), 6200 MD Maastricht, The Netherlands. Tel.: +31 (0) 43 3688666; fax: +31(0) 433688689 .

E-mail address: c.simons@sp.unimaas.nl (C.J.P. Simons).
}

complexity of the disorder has led to the search for intermediate phenotypes with a simpler genetic basis than the dichotomous schizophrenia phenotype in order to facilitate the identification of genetic loci involved in the disorder. Deficits in cognition and information processing, which are prominent in schizophrenia, may be such intermediate phenotype markers. Event-related brain potentials (ERPs) reflect neural activity associated with cognitive information processing (Donchin, 1979) and as such, could be biological intermediate phenotype markers for schizophrenia.

The P300 waveform has been considered as a promising candidate intermediate phenotype. P300 amplitude is thought to index 
brain activity reflecting attention to incoming stimulus information when representations are updated, as well as attribution of salience to deviant stimuli (Polich, 2007; Turetsky et al., 2007). The P300 latency is considered to be a measure of perceptual processing speed (Polich, 2007). Amplitude reduction of the auditory P300 wave is a robust finding in patients with a psychotic disorder and P300 latency has been shown to be delayed in patients compared to healthy controls (Jeon and Polich, 2001; Bramon et al., 2004). Twin and family studies exhibit moderate to high heritability of the P300 amplitude (Polich and Burns, 1987; O'Connor et al., 1994; Wright et al., 2001; Hall et al., 2006) and, although less consistently, suggest that a significant proportion of the variance in P300 latency may be attributed to genetic factors (Katsanis et al., 1997; Almasy et al., 1999; Wright et al., 2001). Studies investigating the P300 waveform in first-degree relatives of patients with a psychotic disorder have produced mixed results. Some family studies have found reductions in P300 amplitudes in siblings (Kidogami et al., 1991; Schreiber et al., 1992; Frangou et al., 1997; Weisbrod et al., 1999; Kimble et al., 2000; Turetsky et al., 2000), whereas other studies did not find differences between siblings and controls (Karoumi et al., 2000; de Wilde et al., 2008; Sumich et al., 2008). In a meta-analysis, Bramon et al. (2005) showed that siblings displayed normal P300 amplitude, but had a significantly prolonged P300 latency.

Reductions in the amplitude of the earlier auditory N100 evoked potential are also found in patients with a psychotic disorder, reflecting deficits in mechanisms involved in initial sensory processing and early selective attention (Strik et al., 1992; Frangou et al., 1997; Laurent et al., 1999). A study of healthy twins suggested that the reduction in N100 amplitude is highly heritable (Anokhin et al., 2007) and there is some evidence that the reduction in N100 amplitude is also seen in first-degree relatives (Blackwood et al., 1991; Frangou et al., 1997; Turetsky et al., 2008).

Thus, the P300 and N100 waveforms both may be potential intermediate phenotypes since both appear to be abnormal in patients, both appear heritable and there is also evidence, although mixed, that both show abnormalities in healthy first-degree relatives. However, biological markers should not only be meaningfully associated with the disorder and be under significant genetic control; they should also be stable over time to be considered as useful intermediate phenotypes (de Geus, 2002). Studies of healthy control subjects suggest that P300 amplitude has good test-retest reliability (Segalowitz and Barnes, 1993; Mathalon et al., 2000; Walhovd and Fjell, 2002; Winterer et al., 2003) and measurements of N100 amplitude reliability are satisfactorily as well (Segalowitz and Barnes, 1993; Kinoshita et al., 1996; Walhovd and Fjell, 2002; Fuerst et al., 2007). Compared to amplitude, ERP latency generally shows lower test-retest reliability (Polich, 1986; Fabiani et al., 1987; Kinoshita et al., 1996). Relatively few studies have reported short-term (days) test-retest reliability in patients with a psychotic disorder and to our knowledge, no study to date has reported separate test-retest reliabilities for siblings.

The aims of the present study were to investigate P300 and N100 components as potential intermediate phenotypes of psychosis. More specifically, the present study investigated whether these ERP components (i) display abnormalities in patients with a psychotic disorder as well as in their unaffected family members, and (ii) show adequate test-retest reliability across control, sibling and patient groups.

\section{Methods}

\subsection{Subjects}

The present study consisted of three groups: (i) 22 patients with a DSM-IV diagnosis of non-affective psychosis (17 schizophrenia, 1 schizophreniform disorder, 2 schizoaffective disorder, 2 psychotic disorder not otherwise specified), (ii) 31 non-psychotic siblings of patients with a non-affective psychosis, and (iii) 39 healthy control participants without a familial history of psychosis. Inclusion criteria were: fluent in Dutch and aged between 18 and 50 years. Subjects were excluded if there was a history of significant head injuries or neurological disorders. All three groups were frequency-matched on age and gender (see Table 1). Patients were recruited from community mental health centres and psychiatric hospitals in the south of the Netherlands and in Belgium. Siblings were recruited through the participating patient, and control participants were recruited from the same geographical regions as the patients through advertising and mailing lists.

Participants were interviewed by trained psychologists using the Comprehensive Assessment of Symptoms and History (CASH; Andreasen et al., 1992). Two verbal subtests (Information and Arithmetic) and two performance subtests (Block Design and Symbol Search) of the Wechsler Adult Intelligence Scale-III (Wechsler, 1997) were used to estimate IQ (Blyler et al., 2000).

The study was approved by the medical ethical committee of Maastricht University Medical Centre. All participants provided written informed consent.

\subsection{Experimental procedure}

Subjects took part in two identical recording sessions, temporally spaced apart by 11 days ( $S D=7.5$, range: $2-44$ days). The oddball paradigm was assessed as part of a larger study, which further included: assessments of cognitive functioning (verbal memory, sustained attention, executive functioning, and processing speed), resting EEG, 40- $\mathrm{Hz}$ steady state response, CNV paradigm, three gamma band paradigms, P50 gating paired click-paradigm and MMN oddball paradigm. The order of administration was fixed. The P300 auditory oddball paradigm was administered within the first $15 \mathrm{~min}$ of the EEG test session. To assess the presence of psychiatric symptoms at the time of testing, the extended Brief Psychiatric Rating Scale (Lukoff et al., 1986) was administered after the second recording session.

\subsection{Auditory oddball paradigm}

Within a simple auditory two-tone oddball paradigm, 576 auditory stimuli were presented binaurally by loudspeaker at an approximately $60-\mathrm{dB}$ sound pressure level. Non-targets $(1000 \mathrm{~Hz}$ tones) and targets (2000 Hz tones) with an immediate rise/fall were presented in a ratio of 7:1 in a pseudo-randomized sequence with a stimulus duration of 50 and a $1000 \mathrm{~ms}$ fixed inter-stimulus interval. Subjects were instructed to fixate their eyes on a central cross displayed on a monitor and to press a button in response to targets only.

\subsection{ERP recording}

Scalp electrode activity was recorded using Neuroscan Synamps and Neuroscan Scan 4.3 software (Neuroscan Inc., Sterling, VA, USA) and was measured at 30 electrode sites of which $\mathrm{Fz}, \mathrm{Cz}$ and $\mathrm{Pz}$ were analysed. $\mathrm{Fz}, \mathrm{Cz}$ and $\mathrm{Pz}$ were chosen for analyses because $\mathrm{N} 100$ and P300 responses are largest on the midline locations, probably due to the fact that midline electrodes pick up both left and right hemisphere activity. Furthermore, so far, most studies examining the N100 and P300 component using oddball paradigms, have presented statistical results of midline electrodes only (e.g. Pontifex et al., 2009). Supplementary Figs. S1 and S2 display the ERPs for all electrode sites. These figures show that largest responses were indeed found on the midline. It was therefore decided to present data from $\mathrm{Fz}, \mathrm{Cz}$ and Pz only. The EEG electrodes 
Table 1

Demographic and clinical variables.

\begin{tabular}{|c|c|c|c|c|c|c|c|c|}
\hline & \multicolumn{2}{|c|}{ Patients $(n=20)$} & \multicolumn{2}{|c|}{ Siblings $(n=28)$} & \multicolumn{2}{|c|}{ Controls $(n=38)$} & \multirow[t]{2}{*}{ Statistic (df) } & \multirow[t]{2}{*}{$p$-Value } \\
\hline & Mean & SD & Mean & SD & Mean & SD & & \\
\hline Age & 29.3 & 6.4 & 29.2 & 7.6 & 28.6 & 9.1 & $F(2.86)=.06$ & .94 \\
\hline Male sex, $n(\%)$ & $13(65 \%)$ & & $17(61 \%)$ & & $24(63 \%)$ & & $\chi^{2}(2)=.10$ & .95 \\
\hline Education $^{\mathrm{a}}$ & 5.6 & 1.7 & 6.1 & 1.9 & 6.0 & 1.7 & $F(2.86)=.53$ & .59 \\
\hline $\mathrm{IQ}^{\mathrm{b}}$ & 97.7 & 16.2 & 114.1 & 17.8 & 113.4 & 15.4 & $F(2.86)=7.36$ & .001 \\
\hline Reaction time & 376 & 83.0 & 297 & 48.8 & 280 & 40.9 & $F(2.86)=20.37$ & $<.0001$ \\
\hline BPRS total $^{\mathrm{c}}$ & 42.0 & 13.9 & 28.3 & 3.6 & 26.6 & 2.1 & $F(2.85)=33.33$ & $<.0001$ \\
\hline \multicolumn{9}{|l|}{ Antipsychotic use } \\
\hline Atypical & $n=12$ & & & & & & & \\
\hline Typical & $n=3$ & & & & & & & \\
\hline
\end{tabular}

\footnotetext{
a Educational level achieved, measured on a nine-point scale from no education (0) to university degree (8).

b IQ was assessed using a short form of the WAIS-III using Information, Block Design, Digit Symbol and Arithmetic.

c Brief Psychiatric Rating Scale total scores.
}

were referenced to the left mastoid. Tin electrodes were used to record bipolarly the vertical (above and below the left eye) and horizontal (at outer canthi of both eyes) electrooculogram (EOG). An electrode at an anterior midline site $(\mathrm{AFz})$ served as ground. Electrode impedances were kept below $5 \mathrm{k} \Omega$. EEG and electrooculogram were digitally filtered with a bandpass of $0.1-100 \mathrm{~Hz}$. Digitization rate and gain were $1000 \mathrm{~Hz}$ and 150 , respectively, and no notch filter was applied.

\subsection{ERP analysis}

Analyses were performed using Neuroscan Scan 4.3 (Neuroscan Inc., Sterling, VA, USA). Data were filtered off-line with a $1 \mathrm{~Hz}$ highpass filter ( $6 \mathrm{~dB} / \mathrm{oct})$. Ocular activity was removed using a regression procedure (Gratton et al., 1983). Epochs were segmented at intervals of $100 \mathrm{~ms}$ pre-stimulus and $1000 \mathrm{~ms}$ post-stimulus. After segmentation, data were filtered using a $30-\mathrm{Hz}$ low-pass filter ( $6 \mathrm{~dB} / \mathrm{oct})$ and data were baseline-corrected. Artefacts were removed both automatically by eliminating epochs that contained signals exceeding $\pm 75 \mu \mathrm{V}$ between $100 \mathrm{~ms}$ pre-stimulus and $500 \mathrm{~ms}$ post-stimulus, and based on visual inspection. Sweeps with incorrect performance were also rejected, that is target tones to which no response was made and non-targets to which a response was made were excluded from analysis. The ERP components for target and non-target tones were analysed separately.

Components were defined as: N100, the most negative peak occurring between 70 and 160 ms post-stimulus; and P300, the most positive peak between 250 and $500 \mathrm{~ms}$ post-stimulus. Latency windows for P300 were defined based on peak latency at Pz. Next, P300 latencies were separately searched for at $\mathrm{Fz}$ and $\mathrm{Cz}$, defining them as the peak value within that chosen window. Latency windows for N100 were defined based on peak latency at $\mathrm{Cz}$ and were separately searched for at $\mathrm{Fz}$ and $\mathrm{Pz}$, defining them as the peak value within the window chosen at $\mathrm{Cz}$. Peak amplitudes were measured from baseline to peak, using the same time windows.

\subsection{Statistical analysis}

The present data have a hierarchical structure. Multiple observations (level 1) were clustered within subjects (level 2), who were part of families (level 3). Multilevel random regression analysis is the method of choice to deal with data consisting of observations at more than one level in terms of unit of analysis, by taking the variability associated with each level of nesting into account (Snijders and Bosker, 1999). The XTMIXED command in STATA 10.0 (StataCorp, 2007) was used to conduct multilevel linear regression analyses, fitted with maximum likelihood methods. Data from test and retest sessions and three midline electrodes ( $\mathrm{Fz}, \mathrm{Cz}, \mathrm{Pz})$ were entered into the regression analyses. For the standard stimuli, there was no clear P300 component in a large proportion of the sample. Therefore, we conducted analyses of the P300 components for target stimuli only, whereas the analyses for the N100 components were conducted for the standard as well as target stimuli. Each ERP variable was assessed in a separate analysis. Sex and age were included as covariates for all regression analyses. The group variable was entered as two dummy variables (siblings, patients) comparing associations with the reference group (controls).

Test-retest reliability was estimated by calculating intraclass correlation coefficients (ICCs) for each of the three midline electrodes (Fz, Cz, Pz), carried out using SPSS (SPSS version 16.0 for Windows; SPSS Inc., Chicago). ICCs take both within-subject as well as between-subject variance into account and therefore provide a better measure of test-retest reliability, compared with, for example, Pearson product moment correlations (Bartko, 1991, 1994; Farahat et al., 2003). ICCs were used in a two-way mixed effects model with consistency and single measurements (Farahat et al., 2003). It was decided a priori that a reliability coefficient of less than .40 would be considered poor, coefficients between $.40-.59$ would be considered fair, coefficients between $.60-.75$ good and coefficients larger than .75 excellent, based on previous accounts of classifying the degree of reliability (Fleiss, 1986; Rentzsch et al., 2008).

\section{Results}

\subsection{Sample}

Due to technical difficulties, two participants of the patient group and one participant of the control group were excluded. Additionally, one participant of the control group was excluded because of use of antidepressive medication and one sibling was excluded because of use of methylphenidate. One patient's EEG data contained excessive artefacts on both occasions; two control subjects had data containing excessive artefacts on a single occasion. These data were excluded from further analyses. Thus, EEG data from the oddball paradigm were available for 20 patients, 28 siblings and 38 healthy control participants, stemming from 68 different families (including 12 patient-sibling couples, 1 patient-sibling-sibling couple, 2 sibling-sibling couples, 2 controlcontrol couples and 7 single patients, 9 single siblings and 34 single controls). Eighty-three of these subjects had data available from both sessions. Table 1 shows demographic and clinical data.

\subsection{ERP data}

Descriptive statistics are depicted in Table 2. Grand average waveforms elicited by standard and target tones are presented in Fig. 1. There were no large or significant differences between groups in the number of sweeps analysed. 
Table 2

P300 and N100 descriptive statistics.

\begin{tabular}{|c|c|c|c|c|c|c|}
\hline & \multicolumn{2}{|c|}{ Patients $(n=20)$} & \multicolumn{2}{|c|}{ Siblings $(n=28)$} & \multicolumn{2}{|c|}{ Controls $(n=38)$} \\
\hline & Mean & SD & Mean & SD & Mean & SD \\
\hline \multicolumn{7}{|c|}{ N100 latency (ms) } \\
\hline Standards & 127 & 11.2 & 127 & 6.3 & 124 & 8.4 \\
\hline Targets & 127 & 12.1 & 128 & 9.2 & 122 & 11.0 \\
\hline \multicolumn{7}{|c|}{ N100 amplitude $(\mu \mathrm{V})$} \\
\hline Standards & -2.9 & 1.8 & -3.6 & 1.9 & -3.9 & 2.4 \\
\hline Targets & -4.1 & 2.9 & -4.8 & 2.3 & -4.0 & 2.9 \\
\hline \multicolumn{7}{|c|}{ P300 latency (ms) } \\
\hline Targets & 332 & 46.0 & 304 & 39.2 & 290 & 38.1 \\
\hline \multicolumn{7}{|c|}{ P300 amplitude $(\mu \mathrm{V})$} \\
\hline Targets & 7.8 & 4.9 & 11.7 & 4.2 & 11.0 & 5.2 \\
\hline
\end{tabular}

\section{3. $N 100$}

For the standard stimuli, N100 latencies of patients differed significantly from controls $(\beta=.42, p=.048)$. Siblings also displayed a significantly longer $\mathrm{N} 100$ latency than controls $(\beta=.38, p=.049)$. Results were similar for target stimuli: patients $(\beta=.41, p=.04)$ as well as siblings $(\beta=.51, p=.001)$ displayed significantly longer N100 latencies compared to controls. As the box plot in Fig. 2 shows, the significant differences between controls and siblings/ patients were not produced by outliers.

A trend towards significance was found for the difference in N100 amplitude between patients and controls for standard stimuli $(\beta=.39, p=.09)$. There was no significant difference in N100 amplitude between patients and controls for target stimuli $(\beta=-.20$, $p=.33$ ), nor were there significant differences in N100 amplitude between siblings and controls (standards: $\beta=.15, p=.49$; targets $\beta=-.23, p=.22$ ).

\section{4. $P 300$}

Patients showed a significantly longer P300 latency compared to controls $(\beta=.94, p<.001)$. The difference in P300 latency in siblings compared to controls, showed a trend towards significance $(\beta=.32, p=.09)$.

Patients showed a significantly reduced P300 amplitude compared to controls $(\beta=-.61, p=.004)$, whereas siblings did not differ significantly from controls $(\beta=.15, p=.44)$.
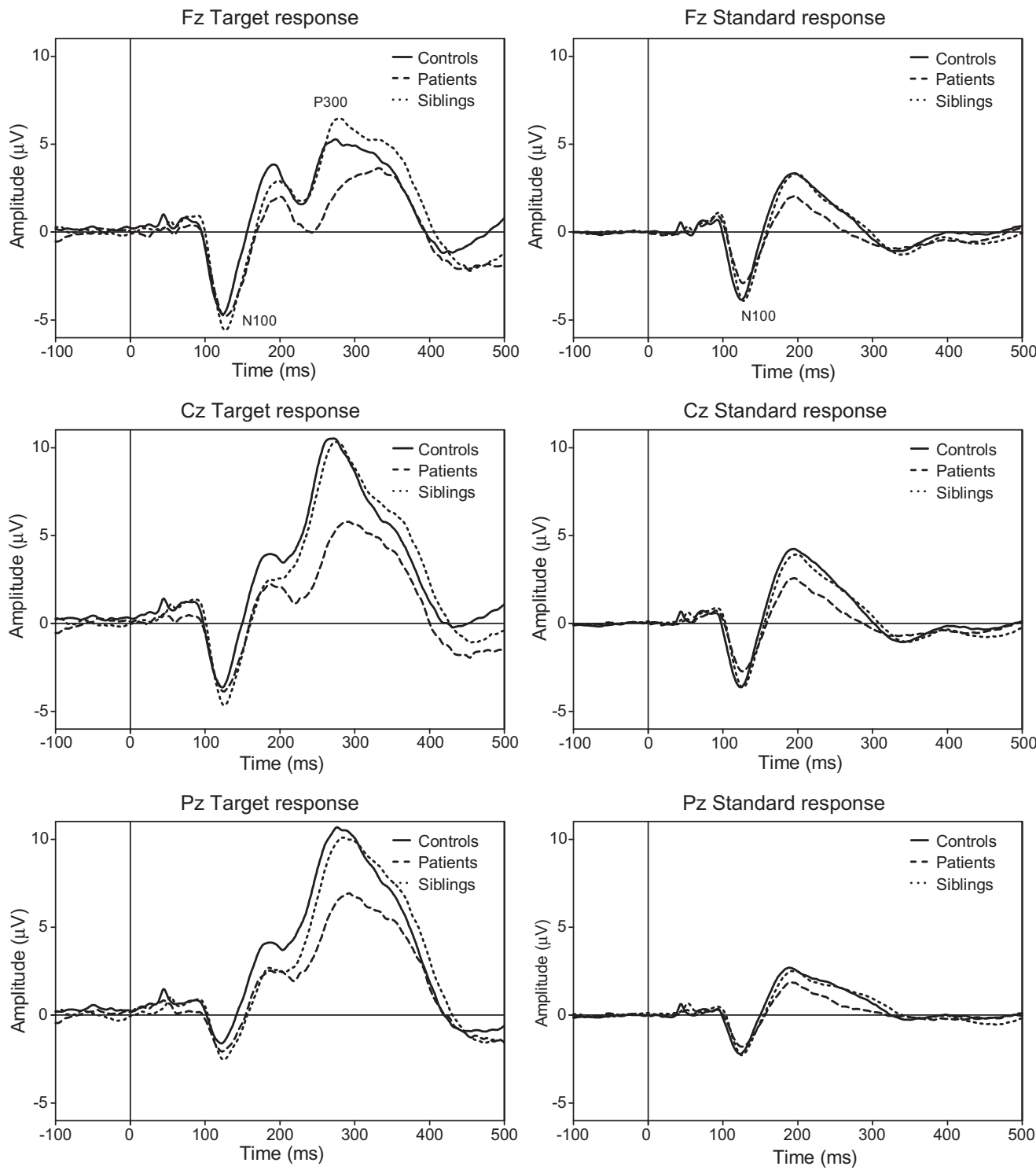

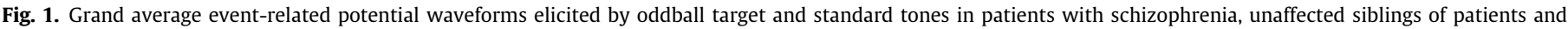
healthy controls. 

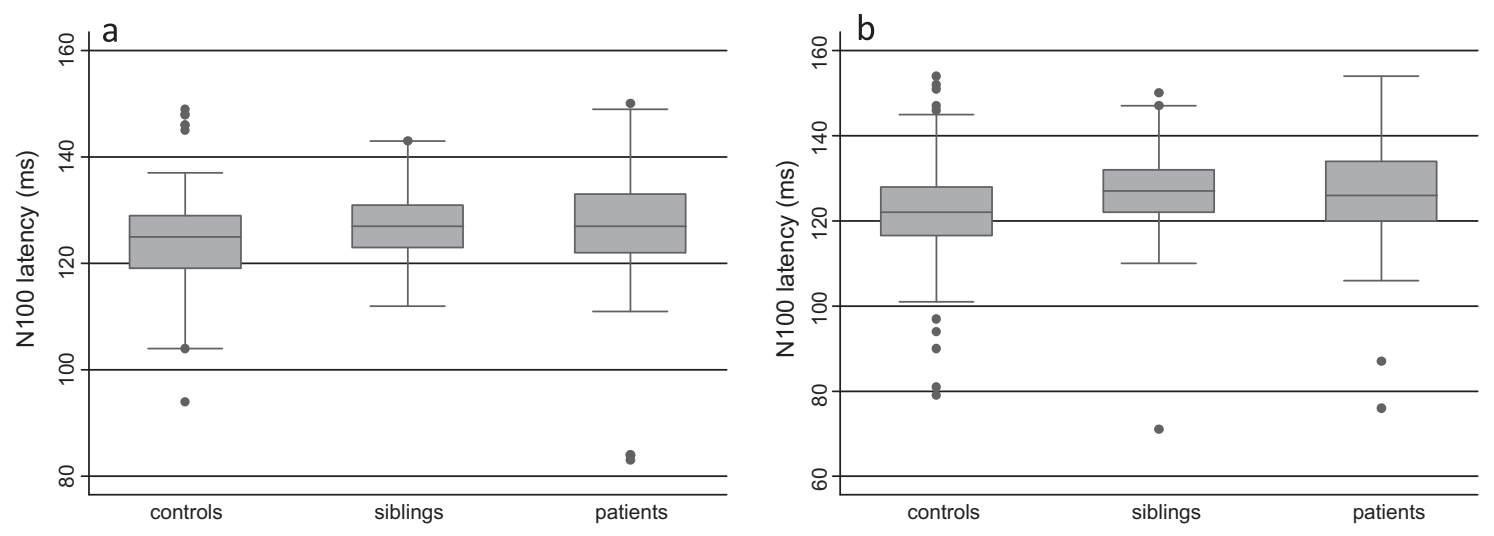

Fig. 2. Box plots for N100 latencies measured at Fz, Cz and Pz, per group for standard stimuli (a) and target stimuli (b).

\subsection{Test-retest reliability}

The intraclass correlation coefficients as a measure of testretest reliability are displayed in Table 3 . Of the 54 ICCs, 22 were larger than .75 and can therefore be classified as evidence of "excellent" test-retest reliability. Eighteen ICCs could be classified as good, nine as fair and five as poor. Test-retest reliability for all P300 amplitude measures was good to excellent. P300 latency was typically less consistent with all P300 latencies ranging from fair to excellent, with the exception of one. All N100 amplitude measures had ICCs ranging from fair to excellent. ICCs for N100 latency were less consistent; testretest reliability for the $\mathrm{N} 100$ latency parameters for standard stimuli was poor in patients and failed to reach statistical significance.

Table 3

Intraclass correlation coefficients. Two-way mixed effect model with consistency and single measurements.

\begin{tabular}{llll} 
& Patients & Siblings & \\
& ICC $(\mathrm{CI})$ & Controls \\
ICC $(\mathrm{CI})$ & & \\
\hline N100 latency standards $(\mathrm{CI})$
\end{tabular}

CI: $95 \%$ confidence interval.

${ }^{*} p<.05$.

*** $p<0.001$.

\section{Discussion}

\subsection{Between-group differences}

The present study confirms previous findings of reduced P300 amplitude (Frangou et al., 1997; Weisbrod et al., 1999; Turetsky et al., 2000; Winterer et al., 2003; de Wilde et al., 2008; Sumich et al., 2008) and latency (Bramon et al., 2005) in patients with a psychotic disorder. The unaffected sibling group did not show any significant differences in P300 latency and amplitude, although a trend towards significance was seen for P300 latency. There have been several negative reports regarding P300 abnormalities in unaffected siblings (Karoumi et al., 2000; de Wilde et al., 2008; Sumich et al., 2008). Task difficulty may influence the magnitude of genetic influences on the variance in P300 amplitude (Polich and Burns, 1987; van Beijsterveldt et al., 1998) and may therefore influence the effect size when comparing a genetic risk group with a healthy control group. The oddball task used in the present study is a relatively easy task, which could explain the lack of effect in siblings. However, other studies suggest comparable heritability for easy and difficult tasks (Katsanis et al., 1997; Wright et al., 2001). In their review, Bharath et al. (2000) point out that studies with difficult tasks found P300 differences in high risk groups, whereas relatively simple oddball tasks did not and suggest that high risk studies should use more attention demanding tasks.

There were no significant differences in N100 amplitude between the three groups, in contrast to previous studies finding amplitude reductions in patients (Strik et al., 1992; Laurent et al., 1999) and in first-degree relatives (Blackwood et al., 1991; Frangou et al., 1997). N100 latency, on the other hand, was significantly delayed in patients and in siblings, for non-target as well as target stimuli, thus suggesting that N100 latency may be a manifestation of familial and possibly genetic liability for psychosis. The results are suggestive of slowed processing of auditory information early in the processing sequence, consistent with findings of abnormalities in other early components such as abnormalities in mismatch negativity (Javitt et al., 1993; Alain et al., 1998; Bramon et al., 2004) and impaired auditory sensory gating (Clementz et al., 1997; Boutros et al., 2009). Slowing of initial auditory processing may have downstream consequences for conscious processing of information, as indexed by delayed peaking of later ERP components such as P300.

\subsection{Reliability}

The reliability of the ERP components recorded with an average interval of 11 days was sound, with the main exception of N100 
latencies for standards in patients. P300 amplitude reliability was good to excellent across electrode site and group (ICC .73-.85). The latency of the P300 was less consistent (ICC .34-.76). This is in line with previous studies applying oddball paradigms, showing good test-retest correlation coefficients $(r)$ for P300 amplitude (.5.8 ) and good, but generally lower coefficients for P300 latency (.4-.7) in healthy controls (Polich, 1986; Fabiani et al., 1987; Segalowitz and Barnes, 1993).

N100 amplitude reliability ranged from fair to excellent across group and electrode (ICC .45-.92), with somewhat higher reliabilities for standard trials than for target trials. Conform previous findings (Walhovd and Fjell, 2002; Fuerst et al., 2007), N100 amplitude measures were overall more robust than latency measures, in line with the findings for the P300 reliability measures. Previous studies suggest that ERP test-retest reliability tends to follow the topographical distribution of the ERP component, and is greatest where the component is maximal (Walhovd and Fjell, 2002; Williams et al., 2005). N100 latency and amplitude reliabilities did indeed appear lower for $\mathrm{Pz}$ than for $\mathrm{Fz}$ and $\mathrm{Cz}$. In contrast, the P300, which peaks at Pz, did not show clear signs of this topographical effect.

Given that test-retest reliabilities for the N100 were lower for the $\mathrm{Pz}$ in all three subject groups and the N100 ERP is less pronounced at $\mathrm{Pz}$, additional analyses were conducted the most relevant electrode $(\mathrm{Cz})$ only. These analyses resulted in similar effect sizes ( $\beta$ 's) as the three-channel model ( $\mathrm{Fz}, \mathrm{Cz}, \mathrm{Pz})$. The delay in N100 latency remains significant in siblings when only looking at $\mathrm{Cz}$ (standards: $\beta=.43, p=.04$; targets: $\beta=.45, p=.04$ ), as does the delay in N100 latency for standard stimuli in patients ( $\beta=.45, p=.047)$. The delay in N100 latency for targets just misses significance in patients, due to a reduction in power, but with an effect size similar to the three-channel model $(\beta=.43, p=.07)$. Thus the analyses restricted to the $C z$ electrode suggest that the N100 latency delay seen in siblings and patients was not decisively influenced by the Pz electrode.

The usefulness of the P300 component as a biological marker for schizophrenia has been questioned, since it is limited by its lack of specificity, e.g. abnormalities in P300 have been reported in other clinical populations and in family members at risk for other neuropsychiatric disorders, such as alcoholism (Hill et al., 1999), bipolar disorder (Schulze et al., 2008) and Alzheimer's disease (Boutros et al., 1995). Furthermore, oddball paradigms and the electrophysiological methods used in family studies of schizophrenia do not show uniformity, thereby complicating comparisons between studies on test-retest reliability.

\subsection{Limitations}

Siblings and controls were screened for psychotic disorders and affective disorders and were excluded if they had a lifetime history of psychotic disorder. Six of the siblings in the study sample and six controls met criteria for a lifetime history of major depressive disorder. Since P300 amplitude may show abnormalities in unipolar depression (Gangadhar et al., 1993), including subjects with a diagnosis of major depressive disorder may influence the results. However, in depression, P300 abnormalities appear state-dependent and all siblings and controls with a lifetime history of depression were currently in remission.

The study included patient-sibling pairs as well as single patients and single siblings. It cannot be excluded that the study was biased toward siblings who either do not share the risk gene combinations. Although the significant difference in siblings compared to control subjects for N100 latency suggests that the siblings included in the study may share some of the risk gene combinations, bias toward 'healthier' siblings may explain the lack of significant findings for P300 abnormalities in the sibling group.

At the time of testing, most patients were on antipsychotic medication, thereby raising the possibility that some of the observed differences between patients and controls may be caused by medication effects. The delayed N100 latency we found in patients was also found in the sibling group, who did not use any psychotropic medication. The delayed latency can therefore not be related to medication status only.

In summary, abnormalities in P300 component are highly consistent in patients with a psychotic disorder. N100 latency is delayed in patients and in siblings of patients with a psychotic disorder and can be reliably measured in siblings, and for target stimuli also in patients, thereby lending support for the use of N100 latency as a biological marker for psychosis liability.

\section{Acknowledgements}

This study was partially made possible by GROUP (Genetic Risk and Outcome of Psychosis) Maastricht. The study was financially supported by research agreement CSMD Ref No: 002510 from GlaxoSmithKline, R\&D Ltd., Brentford, Middlesex, UK. L.K. was supported by a VIDI Grant from the Netherlands Organisation of Scientific Research, and at times during the study, A.S. received funding from the Netherlands Organisation of Scientific Research (VENI Grant 451-07-011).

\section{Appendix A. Supplementary data}

Supplementary data associated with this article can be found, in the online version, at doi:10.1016/j.clinph.2011.02.033.

\section{References}

Alain C, Hargrave R, Woods DL. Processing of auditory stimuli during visual attention in patients with schizophrenia. Biol Psychiatry 1998;44:1151-9.

Almasy L, Porjesz B, Blangero J, Chorlian DB, O'Connor SJ, Kuperman S, et al. Heritability of event-related brain potentials in families with a history of alcoholism. Am J Med Genet 1999;88:383-90.

Andreasen NC, Flaum M, Arndt S. The comprehensive assessment of symptoms and history (CASH) an instrument for assessing diagnosis and psychopathology. Arch Gen Psychiatry 1992;49:615-23.

Anokhin AP, Vedeniapin AB, Heath AC, Korzyukov O, Boutros NN. Genetic and environmental influences on sensory gating of mid-latency auditory evoked responses: a twin study. Schizophr Res 2007;89:312-9.

Bartko JJ. Measurement and reliability: statistical thinking considerations. Schizophr Bull 1991;17:483-9.

Bartko JJ. Measures of agreement: a single procedure. Stat Med 1994;13:737-45.

Bharath S, Gangadhar BN, Janakiramaiah N. P300 in family studies of schizophrenia: review and critique. Int J Psychophysiol 2000;38:43-54.

Blackwood DHR, St. Clair DM, Muir WJ, Duffy JC. Auditory P300 and eye tracking dysfunction in schizophrenic pedigrees. Arch Gen Psychiatry 1991;48:899-909.

Blyler CR, Gold JM, Iannone VN, Buchanan RW. Short form of the WAIS-III for use with patients with schizophrenia. Schizophr Res 2000;46:209-15.

Boutros N, Torello MW, Burns EM, Wu S-S, Nasrallah HA. Evoked potentials in subjects at risk for Alzheimer's disease. Psychiatry Res 1995;57:57-63.

Boutros NN, Brockhaus-Dumke A, Gjini K, Vedeniapin A, Elfakhani M, Burroughs S, et al. Sensory-gating deficit of the N100 mid-latency auditory evoked potential in medicated schizophrenia patients. Schizophr Res 2009;113:339-46.

Bramon E, Rabe-Hesketh S, Sham P, Murray RM, Frangou S. Meta-analysis of the P300 and P50 waveforms in schizophrenia. Schizophr Res 2004a;70:315-29.

Bramon E, Croft RJ, McDonald C, Virdi GK, Gruzelier JG, Baldeweg T, et al. Mismatch negativity in schizophrenia: a family study. Schizophr Res 2004b;67:1-10.

Bramon E, McDonald C, Croft RJ, Landau S, Filbey F, Gruzelier JH, et al. Is the P300 wave an endophenotype for schizophrenia? A meta-analysis and a family study. NeuroImage 2005;27:960-8.

Cardno AG, Gottesman II. Twin studies of schizophrenia: from bow-and-arrow concordances to Star Wars Mx and functional genomics. Am J Med Genet 2000;97:12-7

Clementz BA, Geyer MA, Braff DL. P50 suppression among schizophrenia and normal comparison subjects: a methodological analysis. Biol Psychiatry 1997; $41: 1035-44$

de Geus EJC. Introducing genetic psychophysiology. Biol Psychol 2002;61:1-10 
de Wilde OM, Bour LJ, Dingemans PM, Koelman JHTM, Boerée T, Linszen DH. P300 deficits are present in young first-episode patients with schizophrenia and not in their healthy young siblings. Clin Neurophysiol 2008;119:2721-6.

Donchin E. Event related potentials: a tool in the study of human information processing. In: Begleiter $\mathrm{H}$, editor. Evoked brain potentials and behaviour. London: Plenum Press; 1979. p. 13-88.

Fabiani M, Gratton G, Karis D, Donchin E. The definition, identification, and reliability of measurement of the P300 component of the event-related brain potential. In: Ackles PK, Jennings JR, Coles MGH, editors. Advances in psychophysiology 1987; vol. 2. Greenwich, CT: JAI Press Inc.; 1987. p. 1-78.

Farahat FM, Rohlman DS, Storzbach D, Ammerman T, Anger WK. Measures of shortterm test-retest reliability of computerized neurobehavioral tests. Neurotoxicology 2003;24:513-21.

Fleiss J. The design and analysis of clinical experiments. New York: John Wiley and Sons; 1986.

Frangou S, Sharma T, Alarcon G, Sigmudsson T, Takei N, Binnie C, et al. The Maudsley Family Study, II: endogenous event-related potentials in familial schizophrenia. Schizophr Res 1997;23:45-53.

Fuerst DR, Gallinat J, Boutros NN. Range of sensory gating values and test-retest reliability in normal subjects. Psychophysiology 2007;44:620-6.

Gangadhar BN, Ancy J, Janakiranaiah N, Umapathy C. P300 amplitude in nonbipolar, melancholic depression. J Affect Disord 1993;28:57-60.

Gottesman II. Schizophrenia genesis: the origins of madness. New York: W.H. Freeman; 1991

Gratton G, Coles MGH, Donchin E. A new method for off-line removal of ocular artifact. Electroencephalogr Clin Neurophysiol 1983:55:468-84.

Hall M, Schulze K, Rijsdijk F, Picchioni M, Ettinger U, Bramon E, et al. Heritability and reliability of P300, P50 and duration mismatch negativity. Behav Genet 2006;36:845-57.

Hill SY, Yuan H, Locke J. Path analysis of P300 amplitude of individuals from families at high and low risk for developing alcoholism. Biol Psychiatry 1999;45:346-59.

Javitt DC, Doneshka P, Zylberman I, Ritter W, Vaughan HG. Impairment of early cortical processing in schizophrenia: an event-related potential confirmation study. Biol Psychiatry 1993;33:513-9.

Jeon Y-W, Polich J. P300 asymmetry in schizophrenia: a meta-analysis. Psychiatry Res 2001;104:61-74.

Karoumi B, Laurent A, Rosenfeld F, Rochet T, Brunon A-M, Dalery J, et al. Alteration of event related potentials in siblings discordant for schizophrenia. Schizophr Res 2000;41:325-34.

Katsanis J, Iacono WG, Mcgue MK, Carlson SR. P300 event-related potential heritability in monozygotic and dizygotic twins. Psychophysiology 1997;34:47-58

Kidogami Y, Yoneda H, Asaba H, Sakai T. P300 in first degree relatives of schizophrenics. Schizophr Res 1991;6:9-13.

Kimble M, Lyons M, O'Donnell B, Nestor P, Niznikiewicz M, Toomey R. The effect of family status and schizotypy on electrophysiologic measures of attention and semantic processing. Biol Psychiatry 2000;47:402-12.

Kinoshita S, Inoue M, Maeda H, Nakamura J, Morita K. Long-term patterns of change in ERPs across repeated measurements. Physiol Behav 1996;60:1087-92.

Laurent A, Garcia-Larréa L, d'Amato T, Bosson J-L, Saoud M, Marie-Cardine M, et al. Auditory event-related potentials and clinical scores in unmedicated schizophrenic patients. Psychiatry Res 1999;86:229-38.

Lukoff D, Nuechterlein KH, Ventura J. Manual for the expanded BPRS. Schizophr Bull 1986;12:594-602.

Mathalon DH, Ford JM, Pfefferbaum A. Trait and state aspects of p300 amplitude reduction in schizophrenia: a retrospective longitudinal study. Biol Psychiatry 2000;47:434-49.
O'Connor S, Morzorati S, Christian JC, Li T-K. Heritable features of the auditory oddball event-related potential: peaks, latencies, morphology and topography. Electroencephalogr Clin Neurophysiol 1994;92:115-25.

Polich J. Normal variation of P300 from auditory stimuli. Electroencephalogr Clin Neurophysiol 1986;65:236-40.

Polich J. Updating P300: an integrative theory of P3a and P3b. Clin Neurophysiol 2007; $118: 2128-48$

Polich J, Burns T. P300 from identical twins. Neuropsychologia 1987;25:299-304.

Pontifex MB, Hillman CH, Polich J. Age, physical fitness, and attention: P3a and P3b Psychophysiol 2009;46:379-87.

Rentzsch J, Jockers-Scherübl MC, Boutros NN, Gallinat J. Test-retest reliability of P50, N100 and P200 auditory sensory gating in healthy subjects. Int J Psychophysiol 2008;67:81-90.

Schreiber H, Stolz-Born G, Kornhuber HH, Born J. Event-related potential correlates of impaired selective attention in children at high risk for schizophrenia. Bio Psychiatry 1992;32:634-51.

Schulze KK, Hall M-H, McDonald C, Marshall N, Walshe M, Murray RM, et al. Auditory P300 in patients with bipolar disorder and their unaffected relatives. Bipolar Disord 2008;10:377-86.

Segalowitz SJ, Barnes KL. The reliability of ERP components in the auditory oddball paradigm. Psychophysiology 1993;30:451-9.

Snijders T, Bosker R. Multilevel analysis: an introduction to basic and advanced multilevel modeling. London: SAGE publications Ltd; 1999.

StataCorp: Stata Statistical Software: Release 10. College Station, TX: Statacorp LP 2007.

Strik WK, Dierks T, Böning J, Osterheider M, Caspari A, Körber J. Disorders of smooth pursuit eye movement and auditory N100 in schizophrenic patients. Psychiatry Res 1992;41:227-35.

Sumich A, Kumari V, Dodd P, Ettinger U, Hughes C, Zachariah E, et al. N100 and P300 amplitude to Go and No-Go variants of the auditory oddball in siblings discordant for schizophrenia. Schizophr Res 2008;98:265-77.

Turetsky BI, Cannon TD, Gur RE. P300 subcomponent abnormalities in schizophrenia: III. Deficits in unaffected siblings of schizophrenic probands. Biol Psychiatry 2000;47:380-90.

Turetsky BI, Calkins ME, Light GA, Olincy A, Radant AD, Swerdlow NR Neurophysiological endophenotypes of schizophrenia: the viability of selected candidate measures. Schizophr Bull 2007;33:69-94.

Turetsky BI, Greenwood TA, Olincy A, Radant AD, Braff DL, Cadenhead KS, et al. Abnormal auditory N100 amplitude: a heritable endophenotype in first-degree relatives of schizophrenia probands. Biol Psychiatry 2008;64:1051-9.

van Beijsterveldt CEM, Molenaar PCM, de Geus EJC, Boomsma DI. Individual differences in P300 amplitude: a genetic study in adolescent twins. Biol Psycho 1998;47:97-120.

Walhovd KB, Fjell AM. One-year test-retest reliability of auditory ERPs in young and old adults. Int J Psychophysiol 2002;46:29-40.

Wechsler D. WAIS-III administration and scoring manual. San Antonia, TX: The Psychological Corporation; 1997.

Weisbrod M, Hill H, Niethammer R, Sauer H. Genetic influence on auditory information processing in schizophrenia: P300 in monozygotic twins. Biol Psychiatry 1999;46:721-5.

Williams LM, Simms E, Clark CR, Paul RH, Rowe D, Gordon E. The test-retest reliability of a standardized neurocognitive and neurophysiological test battery: “Neuromarker”. Int J Neurosci 2005;115:1605-30.

Winterer G, Egan MF, Raedler T, Sanchez C, Jones DW, Coppola R, et al. P300 and genetic risk for schizophrenia. Arch Gen Psychiatry 2003;60:1158-67.

Wright M, Hansell N, Geffen G, Geffen L, Smith G, Martin N. Genetic influence on the variance in P3 amplitude and latency. Behav Genet 2001;31:555-65. 